\title{
Geological and Geomorphological Applications of Low-Angle Illumination Satellite Imagery in Northern Ireland
}

\author{
Paul J. Gibson \\ Deptartment of Geography \\ St. Patrick's College, Maynooth
}

\begin{abstract}
Some geoscientists consider satellite imagery as having limited research potential due to their inability to elicit useful information. However, their lack of information extraction is often partly caused by a poor understanding of the importance of such parameters as illumination angle or waveband selection. For the analysis of geological or geomorphological features in vegetated terrain, high-angle illumination imagery acquired between March and October reveals little information. However, low-angle illumination imagery $\left(<10^{\circ}\right.$ solar elevation) obtained in December clearly displays many geomorphological and geological structures not apparent at a higher sun angle. The North Antrim End Moraine can easily be mapped as a single feature on a December image. The Tempo-Sixmilecross Fault and Omagh Fault can also be readily mapped at low-angle illumination and the spatial relationships of these faults to associated structures readily determined. In vegetated terrain Thematic Mapper band 5 is superior to Thematic Mapper band 4 for information extraction. This is partly due to the lower reflectance variance for vegetation on Thematic Mapper band 5 compared with Thematic Mapper band 4, thus the continuity of features is not disrupted.
\end{abstract}

Key Index Words: Low-angle illumination, Thematic Mapper band 5, North Antrim End Moraine, Tempo-Sixmilecross Fault, Omagh Fault.

\section{Introduction}

Imagery from unmanned satellites has been available since 1972 when the first of the Landsat Series was launched. Geologists were quick to exploit the synoptic view that such images yielded in order to analyse geological provinces as entities rather than in a piecemeal fashion. The imagery was ideally suited for regional investigations in areas of good exposure (e.g Bentz and Gutman, 1975; Rothery, 1987) but results in temperate terrain, with extensive vegetation cover generally proved disappointing for a number of reasons. Firstly, vegetation precludes all but the most rudimentary lithological division. Consequently, the greatest potential for satellite imagery in such terrain is for structural and geomorphological analysis. In addition, the agricultural "camouflage" effect caused

Irish Geography 26(1) (1993) 58-64, 0075-0078/93/\$3.50 (c) Geographical Society of Ireland, Dublin. by different crop signatures can adversely affect any investigation. Secondly, the early satellites had a relatively coarse spatial resolution of approximately $80 \mathrm{~m}$. However, the current Landsat Thematic Mapper (TM) system has a spatial resolution of $30 \mathrm{~m}$ and acquires its data in 7 wavebands while the French satellite SPOT has a panchromatic mode resolution of $10 \mathrm{~m}$. Thirdly, a lack of understanding by investigators regarding the importance of such parameters as illumination direction, illumination angle and optimum waveband selection resulted in the examination of unsuitable images. The inability of image interpreters to realise the importance of such parameters for information extraction and their consequent lack of useful results led some geoscientists to look upon satellite imagery as "pretty pictures" with no research potential. Selected areas (see Figure 1) in northern Ireland - where there is over $95 \%$ vegetation cover-are examined in order to illustrate that the analysis of 


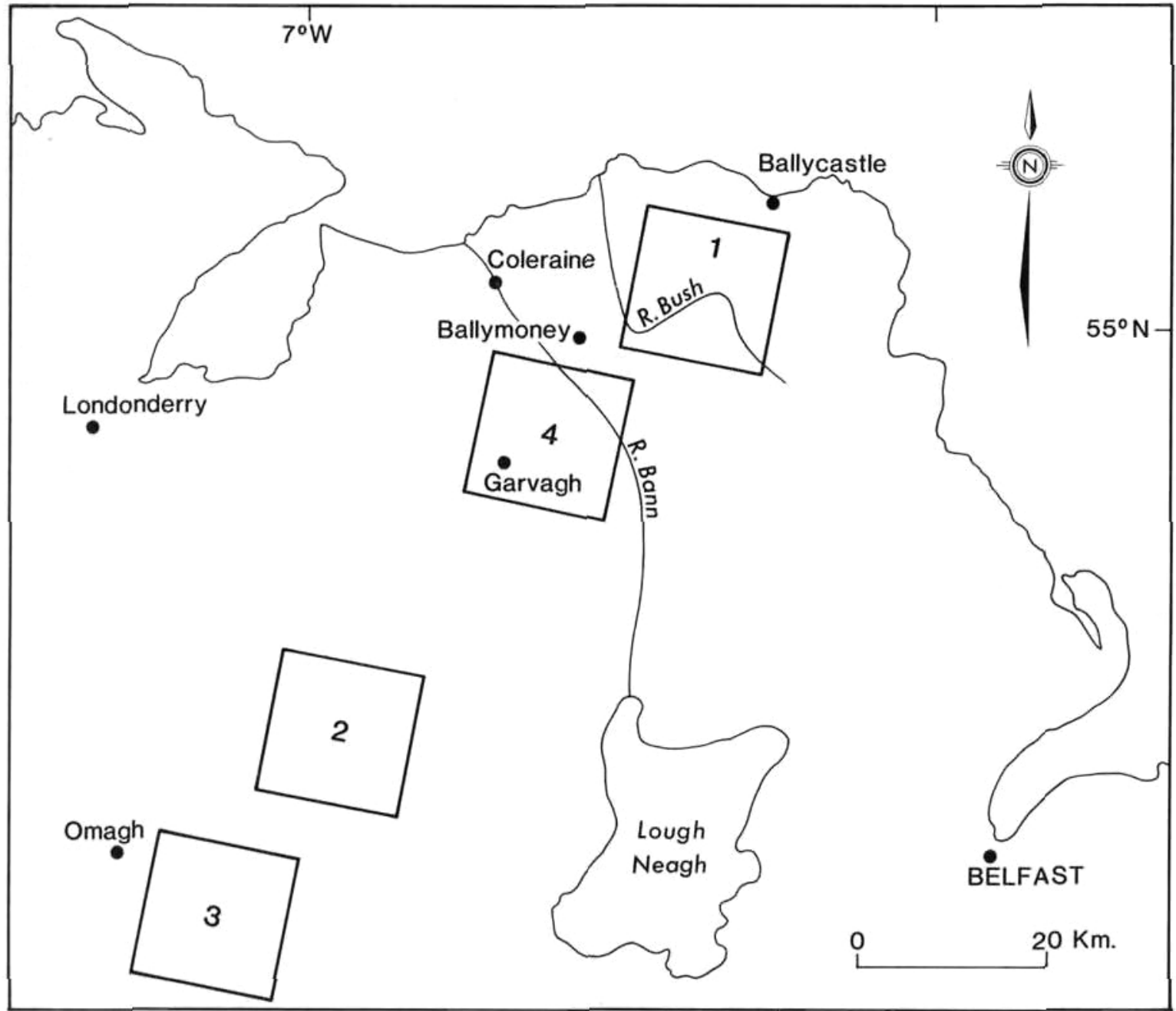

Figure 1: Location map showing the areas investigated by low-angle illumination satellite imagery. 1 : Figures 2 and $3 ; 2$ : Figure 5; 3: Figure 6; 4: Figure 7.

satellite imagery can be an important technique for the acquisition of geological and geomorphological information if the proper image is chosen. Apart from applying a histogram equalization contrast stretch, the images illustrated here have not been digitally processed.

\section{Image Interpretation}

A Thematic Mapper image of part of north Antrim (1, Figure 1) is shown in Figure 2. The data from which the image was produced were acquired on 23/4/87 when the sun was relatively high in the sky. The illumination angle was about $35^{\circ}$. Little information can be obtained from this high solar elevation image. South of Armoy (A, Figure 2) the River Bush which flows in a general northerly direction turns through a right angle to flow WSW though from the image no obvious control on its course can be observed. The same area is displayed on an image obtained in December (Figure 3 ) when the solar elevation was $8^{\circ}$, and interpreted in Figure 4. The low-angle illumination imagery clearly displays NE/SW-trending sinuous ridges which form part of the North Antrim End Moraine which marks the southern limit of the Scottish ice advance during the late Midlandian (Stephens et al. 1975). The formation of this moraine blocked the former northerly flow of the River Bush which was 


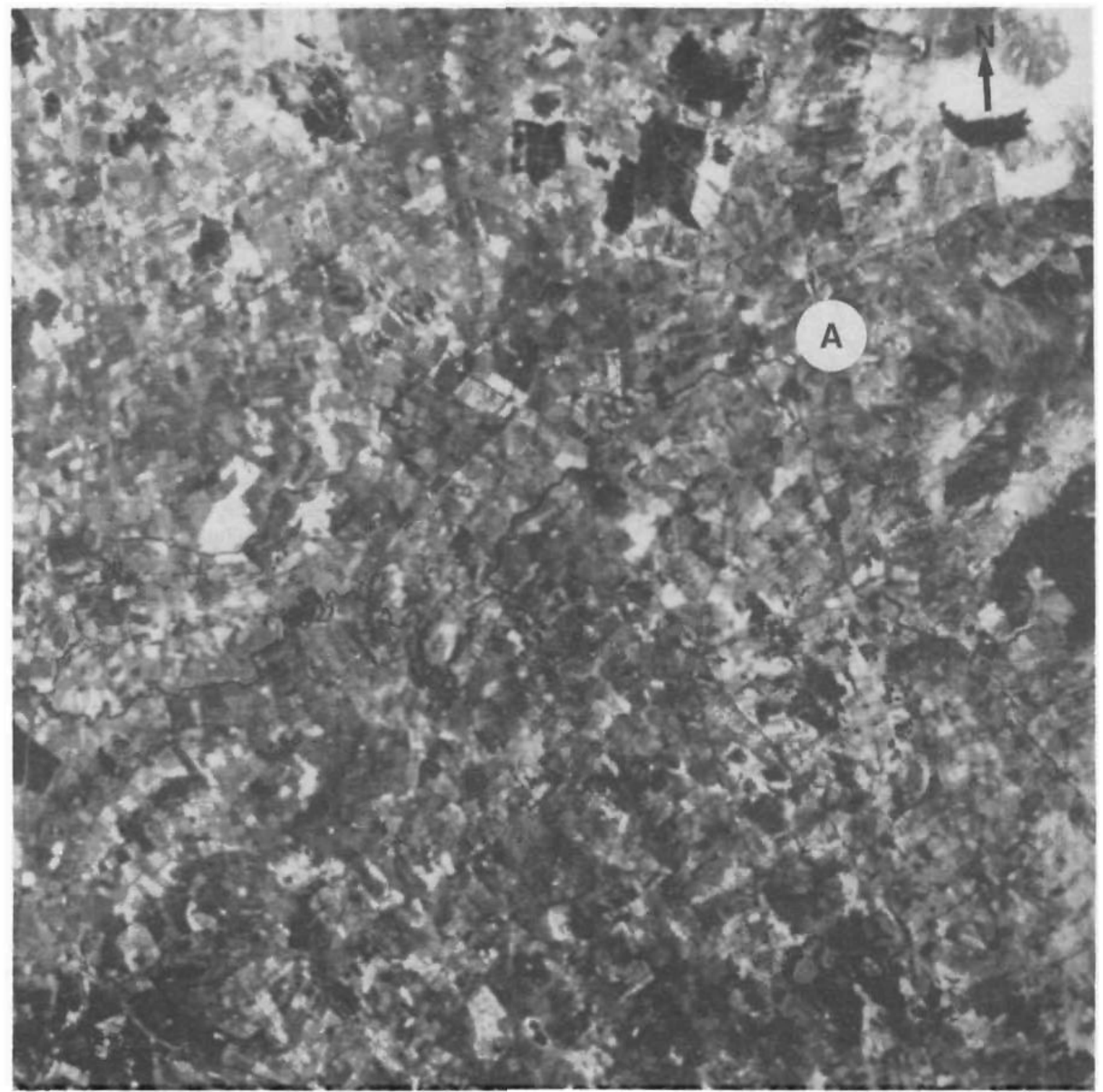

Figure 2: Thematic Mapper band 5 high-angle illumination image. No geological or geomorphological features can be observed. Area covers approximately $15 \times 15 \mathrm{~km}$. A: Armoy.

diverted southwestwards before breaching the moraine $6 \mathrm{~km}$ northeast of Ballymoney. A distinct textural change is also observed across the moraine on the lowangle illumination imagery which is not observed at a higher illumination angle. To the southeast the mottled "hummocky" signature is due to extensive drumlins which are absent north of the moraine. In the NW a previously undescribed linear ribbed moraine can be observed. Both images (Figures 2 and 3) are of TM band $5(1.55-1.7 \mu \mathrm{m})$. Scattering in the atmosphere is inversely proportional to wavelength and TM5 is virtually unaffected by such haze compared with TM1 or TM2 which acquire data at shorter wavelengths. Also, the TM5 waveband is in a part of the electromagnetic spectrum in which the range of reflectance signatures for vegetation is reduced compared with for example TM4. Consequently, using TM5 reduces the chequerboard reflectance response that is obtained with TM4 which disrupts the visual continuity of geological or geomorphological features 


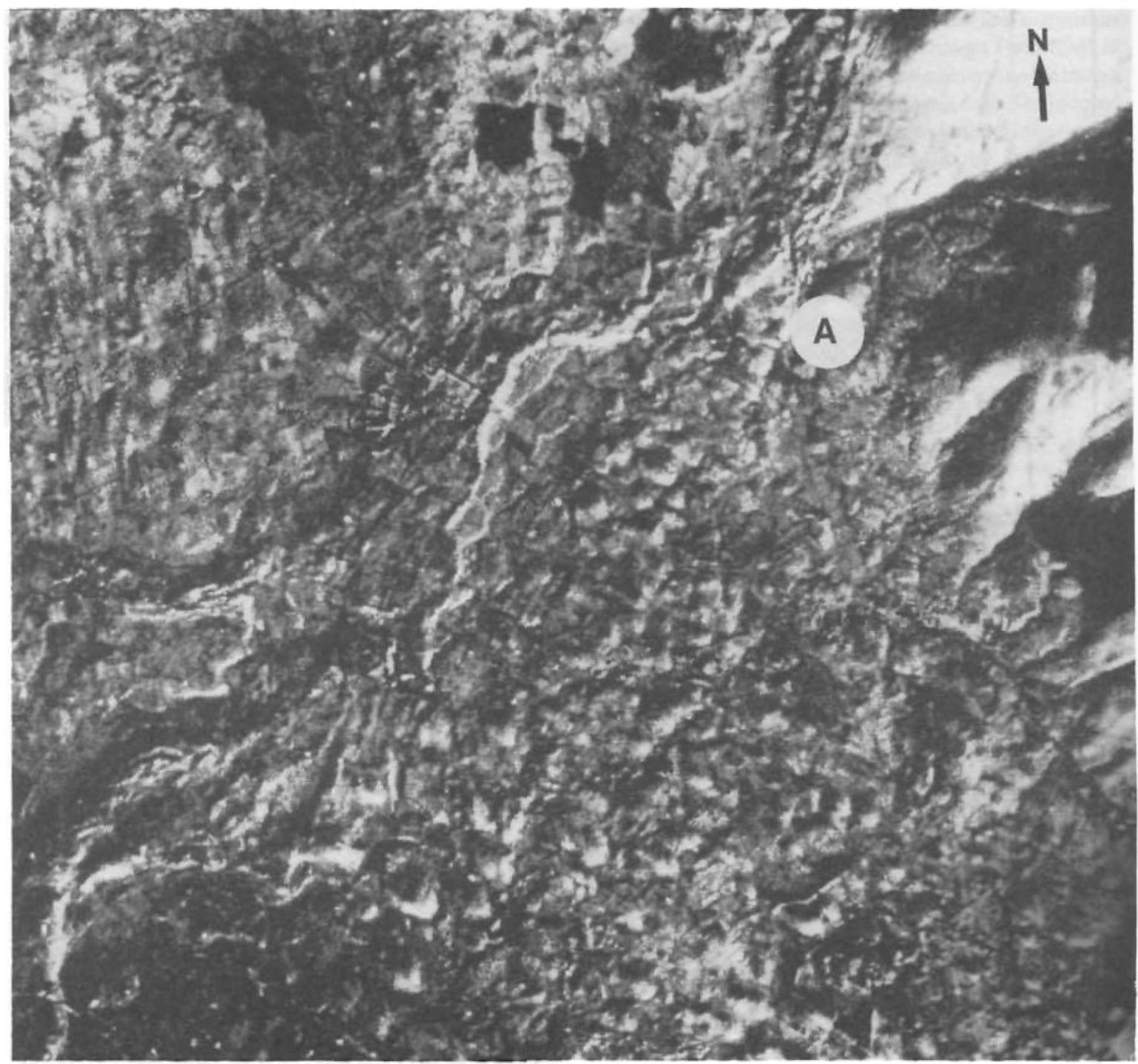

Figure 3: Thematic Mapper band 5 low-angle illumination image covering the same area as Figure 2. The sinuous ridges of the North Antrim End Moraine are accentuated due to the low illumination angle and because they trend at right angles to the illumination direction. The many drumlins to the south of the moraine yield a mottled texture. The ribbed moraine to the northwest is not as clearly shown because of its orientation. A: Armoy. Area approximately $15 \times 15 \mathrm{~km}$.

(Drury, 1986). In addition the surface properties of vegetation in agricultural terrain tend to be less variable in winter (Figure 3 ) than in spring (Figure 2) which also aids structural interpretation. A false colour composite (even one including TM5 at low-angle illumination) while possibly more aesthetically pleasing, is inferior to TM5 alone for information extraction when dealing with geological or geomorphological structures. This is because the modulation transfer functions for the human visual system for colour and monochromatic viewing are markedly different. The chromatic response for the retina decreases sharply above a frequency of 1 cycle/ degree whereas for monochromatic viewing the maximum modulation is obtained at a much higher frequency of 7 cycles/degree (Drury, 1990). Thus the human eye, which is the medium by which an interpreter analyses an image, is more efficient at acquiring 


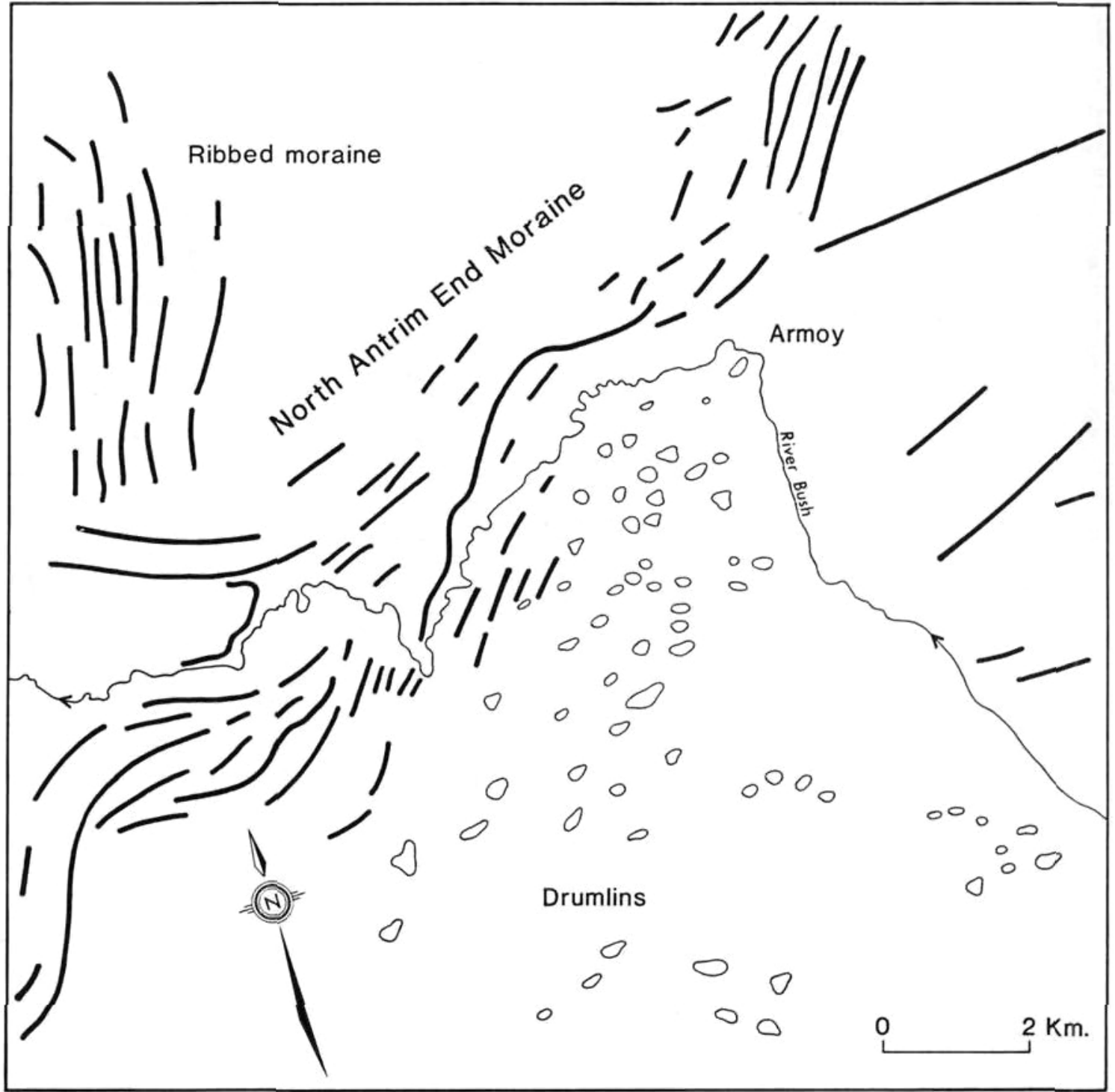

Figure 4: Interpretation of low-angle illumination image shown in Figure 3. The River Bush has had its course diverted by the moraine to flow WSW.

information regarding high frequency linear features (such as faults, eskers, moraines, scarps) in black and white than in colour.

Figures 5-7 illustrate other examples of TM5 imagery taken at a low-angle illumination. In all cases features can be observed which can not readily be seen at a higher sun angle.

Part of the Omagh Fault, one of the most significant geological structures in northern Ireland is shown in Figure 5 by a pronounced tonal and textural break which trends ENE/WSW across the image. Geological information can be indirectly obtained from this image even though there is an extensive vegetation cover because the vegetation type/density is partly controlled by relief which is a function of the underlying rock type. The rocks to the southeast have generally lower relief and are formed mainly of Ordovician volcanics and the Basic Complex of Tyrone (GSNI, 1977). To the northwest a very different signature can be observed, a smoother texture and more variable tone due to the orientation of the slopes. Dalradian lithologies occur in this part of the Sperrin mountains, mainly the 


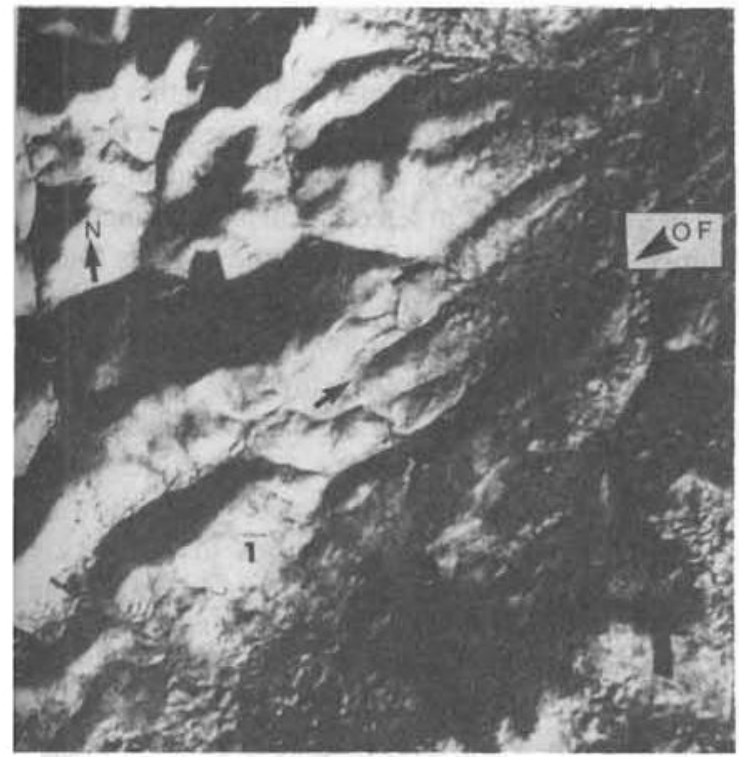

Figure 6: Part of the Tempo-Sixmilecross Fault (T-T) at lowangle illumination. Southeast of the fault shorter WNW/ ESE-trending faults can be seen. Area approximately $15 \times 15 \mathrm{~km}$.

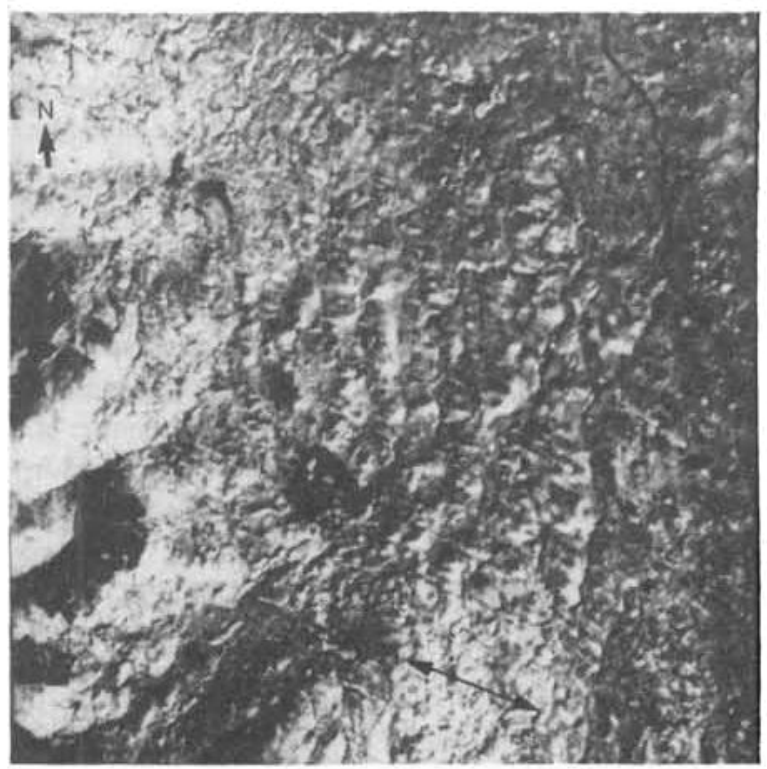

Figure 5: Thematic Mapper band 5 low-angle illumination image of the southern Sperrins. The Omagh Fault (OF) is shown by ENE/WSW-trending discontinuity across the image separating the Dalradian in the northwest from Ordovician volcanics in the southeast. Arrows shows parallel lineaments. 1: tonal and textural change across the fault. Area approximately $15 \times 15 \mathrm{~km}$.

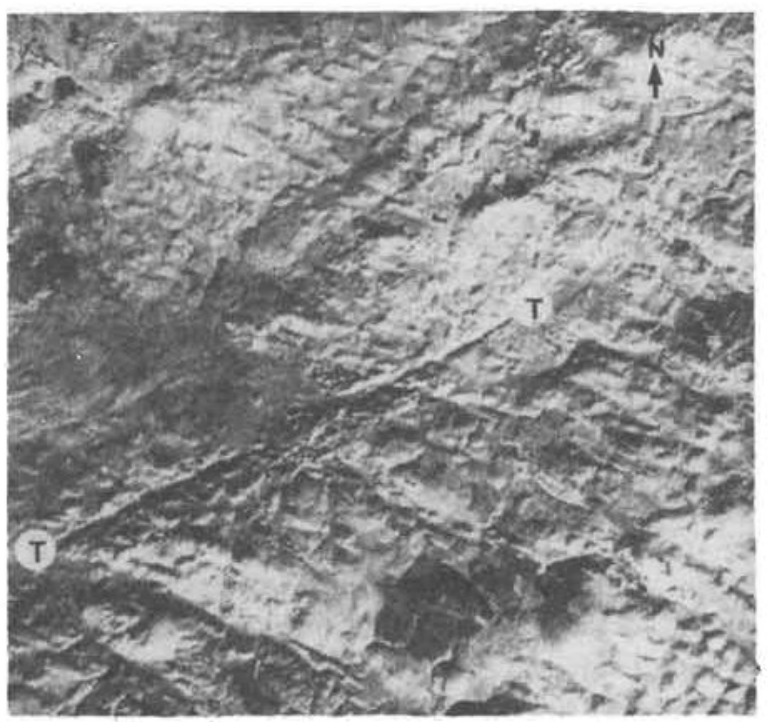

Figure 7: Low-angle illumination image of the Garvagh area. The River Bann can be seen in the northeast. The area is characterised by a distinct WNW/ESE-trending fabric (parallel to arrow) formed from streamlined topography probably caused by ice movements. Area approximately $15 \times 15 \mathrm{~km}$. 
Glenelly and Mullaghcarn schists. The Omagh Fault is accentuated at a low-illumination angle because it is marked by a steeply incised valley (OF, Figure 5) and a marked textural change (1, Figure 5) and because it runs approximately normal to illumination direction. Other lineaments can be observed parallel to the fault (arrowed) which probably represent allied structures.

The Tempo-Sixmilecross Fault (T-T, Figure 6) is the most prominent structure on this low-angle image and is not evident at a higher sun angle. It strikes ENE/ WSW and forms the northern boundary for a number of shorter WNW/ESE-trending faults which are expressed as valleys. In the northern half of the image, short WNW/ESE-striking lineaments can be observed which do not correlate with known faults. Their signature suggests orientated topographic ridges formed of superficial deposits and are probably caused by ice movement.

Analysis of low-angle illumination imagery in the Garvagh area (Figure 7) shows a pervasive NW/SEtrending fabric formed of streamlined topography. This is similar to the appearance of glacial features observed on satellite imagery in the Clew Bay area (Coxon and Brown, 1991) and is a probable indicator of former ice movement direction.

\section{Conclusions}

Gibson

Satellite imagery is a useful technique that can be employed by geoscientists in temperate terrain. However, its usefulness is highly dependent on the skill of the interpreter in selecting an image which will optimise the information. In this study it was found that TM5 acquired at a low-angle illumination revealed many geological and geomorphological features which were not apparent on other images. In addition, structures such as the North Antrim End Moraine could be viewed in its entirety. Satellite imagery is especially useful as a reconnaissance tool, allowing the spatial relationships of features to be quickly evaluated and in targeting areas where fieldwork can be concentrated.

\section{Acknowledgements}

I would like to thank Jim Keenan, St. Patrick's College, Maynooth for the preparation of the figures and imagery. The images were produced using ERDAS software at the Department of Environmental Studies, University of Ulster, Coleraine.

\section{References}

BENTZ, F. P. AND GUTMAN, S. I. (1975) Landsat data contributions to hydrocarbon exploration in foreign regions. Proceedings of the First Annual William T. Pecora Symposium, Sioux falls, South Dakota, Geological Survey Professional Paper 1015, 83-92.

COXON, P. and BROWN, P. (1991) Glacial deposits and landforms of central and western Ireland, in, Ehlers, P., Gibbard, P. L. and Rose, J. (eds.) Glacial Deposits in Great Britain and Ireland. A. A. Balkema, 355-365. (580pp).

DRURY, S. A. (1990) A Guide to Remote Sensing: Interpreting Images of the Earth. Oxford Science Publications 199pp.
DRURY,S. A. (1986) Remote Sensing of geological structure in temperate agricultural terrains, Geological Magazine 123, 113-121.

GSNI(1977) Geological Map of Northern Ireland. 1:250,000. Geological Survey of Northern Ireland, H.M.S.O., Belfast.

ROTHERY, D. A. (1987) Improved discrimination of rock units using Landsat Thematic Mapper imagery of the Oman ophiolite, Journal of the Geological Society, London, 144, 587-97.

STEPHENS, N., CREIGHTON, J. R. and HANNON, M.A. (1975) The late Pleistocene period in North-eastern Ireland: an assessment, Irish Geography 8, 1-23. 